\title{
Clinical Presentations and Genetic Analyses of Patients with Multiple Endocrine Neoplasia Type 2A: A Single Thai Tertiary Center Experience
}

Nitchakarn Laichuthai ${ }^{1}$, M.D., Natnicha Houngngam², M.Sc., Thiti Snabboon ${ }^{1,2}$, M.D., Sarat Sunthornyothin ${ }^{1,2}$, M.D.

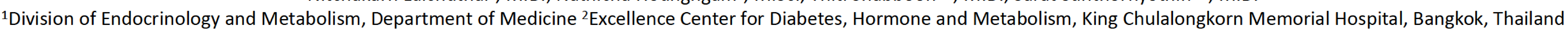

\section{Background}

Multiple endocrine neoplasia type 2A (MEN 2A) is an autosomal dominant disorder characterized by the presence of medullary thyroid carcinoma(MTC), pheochromocytoma and/or primary hyperparathyroidism (PHP). The associated Hirschsprung's disease and cutaneous lichen amyloidosis can be present or absent. The prevalence of MEN 2A is approximately $1: 25,000 .^{1}$

MEN2A diagnosis is based on the presence of one of these tumors and genetic testing to identify a germline mutation, which has good genotypic-phenotypic correlation with regard to aggressiveness of MTC, time of onset of MTC and the presence and absence of other endocrine tumor. ${ }^{2-4}$ The recognition that certain RET mutation may guide the management of patients and their relatives. ${ }^{5}$

\section{Objectives}

To analyze clinical and genetic data of patients with MEN2A at King Chulalongkorn Memorial Hospital, Chulalongkorn University

\section{Materials and Methods}

A retrospective study of 5 probands and 5 family members diagnosed as MEN2A at our center during 2000-2015 was performed. Direct sequencing of the RET gene successfully identified all mutant alleles of the affected individuals. Demographic data, clinical profiles, mutation types and genotype-phenotype correlation were analyzed.

\section{Results}

- 10 RET-carried subjects (5 probands + 5 family members)

- Probands: 3 males and 2 females, age 31-46 year

- Family members: 2 males and 3 females, age 2-50 years

- RET gene: direct sequencing

- Analysis: Clinical profiles, Mutation type, genotype-Phenotype correlation

- At the diagnosis, four probands had pheochromocytoma and MTC whereas the other one developed all three.

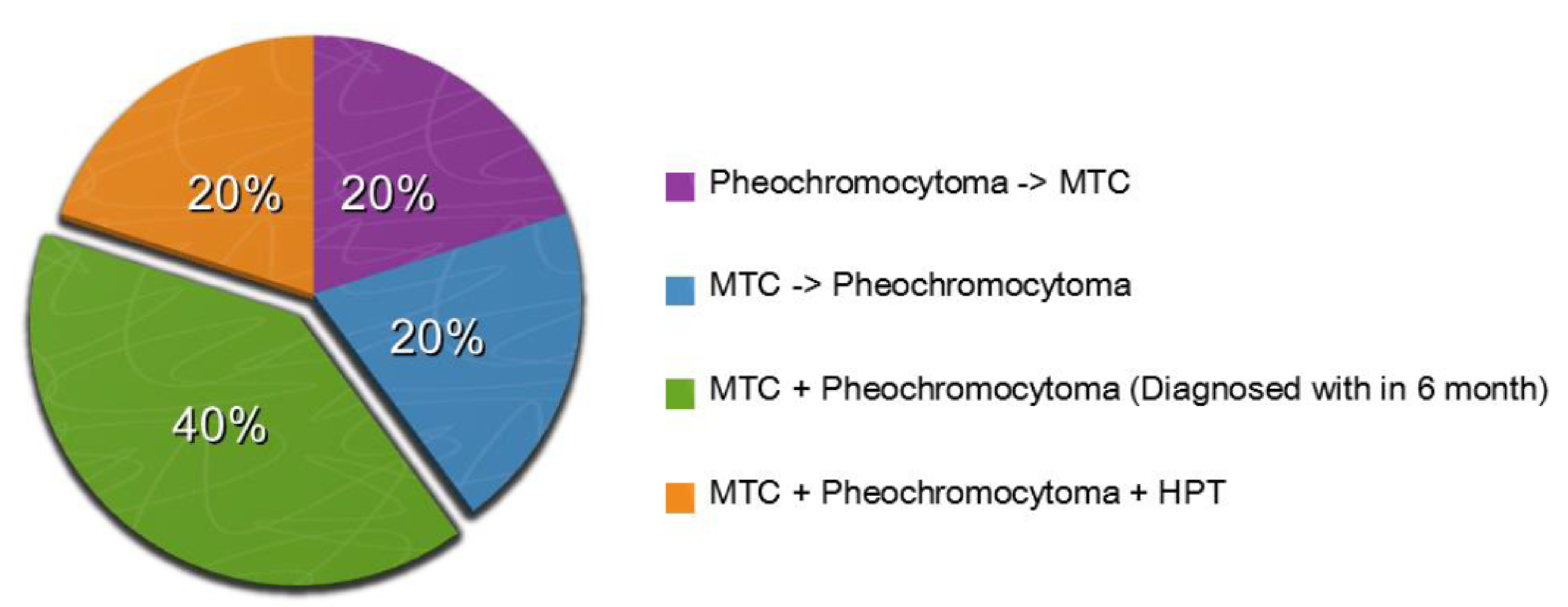

Figure 1. Clinical presentations of the probands
Results

MTC

- Mean age at diagnosis 36.86 years [13 - 54 years] (100\%)

- 60\% Multifocal

- Two of the probands initially presented with MTC with multiple foci at the diagnosis.

- Serum calcitonin 101 [17.4-1168 pg/ml]

- Lymph node metastasis in $66.67 \%(2 / 3)$ of patients

- No distance metastasis at diagnosis

Pheochromocytoma

- Mean age at diagnosis 41.71 years [range 31 - 51 years]

- Average tumor size $5.4 \mathrm{~cm}$ [range $2-8 \mathrm{~cm}$ ]

- Bilateral pheochromocytoma $50 \%(3 / 6)$

- Benign: $100 \%$

Hyperparathyroidism

- Parathyroid hyperplasia was identified in one case.

None of the probands have cutaneous lichen amyloidosis nor Hirschsprung's disease.

\begin{tabular}{|c|c|c|c|c|c|c|c|c|c|}
\hline \multirow{2}{*}{ Patient } & \multirow{2}{*}{ Gender } & \multirow{2}{*}{ Age at $D x$} & \multirow{2}{*}{ First presentation } & \multicolumn{3}{|c|}{ MEN2A manifestations } & \multirow{2}{*}{$\begin{array}{c}\text { Mutatlon } \\
\text { Exon } 11 \\
\end{array}$} & \multirow{2}{*}{$\begin{array}{l}\text { Follow up } \\
\text { (month) }\end{array}$} & \multirow{2}{*}{ Outcome } \\
\hline & & & & MTC & Pheo & HPT & & & \\
\hline 1 & M & 46 & Pheo & + & Bilateral & - & c6345 & 72 & Remission \\
\hline 2 & M & 32 & MTC & + & Unilateral & - & c6345 & 24 & Remission \\
\hline 3 & M & 38 & Pheo & + & Unilateral & - & c634S & 8 & Remission \\
\hline 4 & $\mathrm{~F}$ & 42 & Pheo & + & Bilateral & $\begin{array}{c}+ \\
\text { (hypcrplasia) }\end{array}$ & C634R & Loss F/U & $\mathrm{N} / \mathrm{A}$ \\
\hline 5 & $\mathrm{~F}$ & 31 & MTC & + & Bilateral & - & C634R & - & Death \\
\hline
\end{tabular}

Table 1. Clinical profile and genetic analysis of the probands

Two distinct mutations which all located in codon 634 of exon 11 in RET proto-oncogene, C634S (60\%) and C634R (40\%), were detected. A prophylactic thyroidectomy based on a classification of RET mutations in an asymptomatic MTC 10year-old girl was performed successfully.

\section{Conclusions from our study}

- RET mutation "hot spot" to codon 634

- High prevalence of MTC and pheochromocytoma

- Low prevalence of hyperparathyroidism

- Screening and early detection of MEN2A mutation carrier are very effective clinical intervention.

- As described in the literature, MTC is usually the first manifestation in patients with MEN2A; however, pheochromocytoma may be the presenting tumor due to its alarming symptoms.

- In this study the identified frequent loci of the RET gene will facilitate the molecular diagnosis of MEN $2 \mathrm{~A}$ in Thai population.

1.Kidd KK, Simpson NE. Search for the gene for multiple endocrine neoplasia type 2A. Recent progress in hormone research. 1990;46:305-41; discussion 41-3.

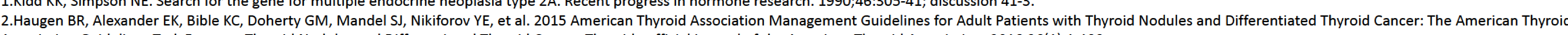
Association Guidelines Task Force on Thyroid Nodules and Differentiated Thyroid Cancer. Thyroid : official journal of the American Thyroid Association. 2016;26(1):1-133.

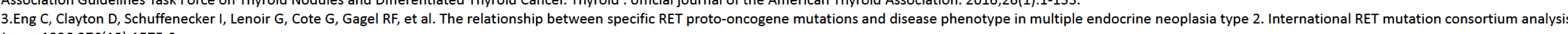
Jama. 1996;276(19):1575-9.

4.Machens A, Niccoli-Sire P, Hoegel J, Frank-Raue K, van Vroonhoven TJ, Roeher HD, et al. Early malignant progression of hereditary medullary thyroid cancer. The New England journal of medicine. 2003;349(16):1517-25.

5.Brandi ML, Gagel RF, Angeli A, Bilezikian JP, Beck-Peccoz P, Bordi C, et al. Guidelines for diagnosis and therapy of MEN type 1 and type 2. The Journal of clinical endocrinology and metabolism. 2001;86(12):5658-71. 